\title{
Prevention of Venous Neointimal Hyperplasia by a Multitarget Receptor Tyrosine Kinase Inhibitor
}

\author{
Sun Hyung Kwon ${ }^{a}$ Li Li $^{b} \quad$ Yuxia He $^{b}$ Jason Chieh Sheng Tey ${ }^{b}$ Huan Li ${ }^{b}$ \\ Ilya Zhuplatov $^{b}$ Seung-Jung Kim ${ }^{d}$ Christi M. Terry ${ }^{b}$ Donald K. Blumenthal ${ }^{a}$ \\ Yan-Ting Shiu ${ }^{\mathrm{b}}$ Alfred K. Cheung ${ }^{\mathrm{b}, \mathrm{c}}$ \\ ${ }^{a}$ Department of Pharmacology and Toxicology and ${ }^{b}$ Division of Nephrology and Hypertension, Department of \\ Medicine, University of Utah, and ' Medical Service, Veterans Affairs Salt Lake City Healthcare System, \\ Salt Lake City, Utah, USA; d Division of Nephrology, School of Medicine, Ewha Womans University, Seoul, South Korea
}

\section{Key Words}

Arteriovenous graft - Neointimal hyperplasia - Perfused organ culture · Sunitinib · Growth factors

\begin{abstract}
Background/Aims: Venous neointimal hyperplasia (NH) is the predominant cause of stenosis in hemodialysis arteriovenous grafts (AVG), but there is currently no clinically used therapy to prevent NH. Methods: A porcine AVG model was used to identify potential pharmacological targets to prevent $\mathrm{NH}$. Sunitinib, a broad-spectrum tyrosine kinase inhibitor, was examined as a potential anti-NH drug utilizing in vitro and ex vivo models. Results: In an in vivo porcine model, PDGF, VEGF and their receptors PDGFR-a and VEGFR-2 were upregulated at the venous anastomosis within 2 weeks after AVG placement, with $\mathrm{NH}$ development by 4 weeks. Sunitinib inhibited PDGF-stimulated proliferation, migration, phosphorylation of MAPK and PI3K/Akt proteins and changes in the expression of cell-cycle regulatory proteins in vascular smooth-muscle cells as well as VEGF-stimulated endothelial cell proliferation in vitro. In an ex vivo model, sig-
\end{abstract}

nificant $\mathrm{NH}$ was observed in porcine vein segments perfused for 12 days under pathological shear stress. Sunitinib (100 $\mathrm{nM}$ ) inhibited $\mathrm{NH}$ formation, with the intima-to-lumen area ratio decreasing from $0.45 \pm 0.25$ to $0.04 \pm 0.02(p<0.05)$ with treatment. Conclusion: These findings demonstrate sunitinib to be a potential $\mathrm{NH}$-preventive drug as well as the utility of an ex vivo model to investigate pharmacotherapies under pathophysiological flow conditions.

ㄷ) 2016 S. Karger AG, Basel

\section{Introduction}

While a well-functioning native arteriovenous fistula is the preferred form of vascular access for chronic hemodialysis, up to $60 \%$ of arteriovenous fistulas fail to mature [1-4]. A synthetic arteriovenous graft (AVG), consisting of expanded polytetrafluoroethylene tubing anastomosed between an artery and vein, is a common alternative.

S.H.K. and L.L. contributed equally to this work.

\section{KARGER 125}

(c) 2016 S. Karger AG, Base

$1018-1172 / 16 / 0524-0244 \$ 39.50 / 0$

E-Mail karger@karger.com

www.karger.com/jvr
Dr. Yan-Ting Shiu or Dr. Alfred K. Cheung

Division of Nephrology and Hypertension, University of Utah School of Medicine 85 North Medical Drive East

Salt Lake City, UT 84112 (USA)

E-Mail y.shiu@ @sc.utah.edu or alfred.cheung@hsc.utah.edu 
AVGs do not require maturation and can typically be used within 2-3 weeks of placement. However, AVGs are associated with high stenosis rates, followed by thrombosis and occlusion, with 50 and $75 \%$ failure rates at 1 and 2 years, respectively, after implantation $[5,6]$. Currently, AVG stenosis is treated by angioplasty, but the vascular wall injury associated with this procedure predisposes to restenosis [3].

Neointimal hyperplasia $(\mathrm{NH})$ accounts for practically all stenotic lesions associated with AVGs [3, 7]. Histologically, $\mathrm{NH}$ consists of proliferating smooth-muscle cells (SMCs) and myofibroblasts, mostly derived from the medial and the adventitial layers of the vessel wall [6-12]. Progressive $\mathrm{NH}$ occurs much more frequently at the graft-venous anastomosis (hereafter referred to as venous anastomosis) than at the graft-arterial anastomosis (arterial anastomosis) of an AVG $[3,7,13]$. The AVG shunts arterial blood flow directly into the vein, exposing the vein to high blood pressures and pulsatile and disturbed flow patterns, resulting in highly aberrant wall shear stress (WSS). In addition to the multiple pathogenic factors, such as inflammation enhanced by the foreign graft material and surgical damage to the protective adventitia and endothelium, drastically altered hemodynamics at the venous anastomosis likely predisposes this location to $\mathrm{NH}$ development.

The early stage of NH development requires the growth and migration of cells in the vascular wall. Platelet-derived growth factor (PDGF) and vascular endothelial growth factor (VEGF) have been implicated in the pathogenesis of NH in arterial injury models [14-18], and the receptor for VEGF (VEGFR) and the receptor for PDGF (PDGFR) have been reported to mediate mechanotransduction signaling in vascular endothelial cells (ECs) and SMCs, respectively $[19,20]$. We examined the expression of PDGF and VEGF and their receptors in a porcine AVG model. Sunitinib, a multitarget receptor tyrosine kinase (RTK) inhibitor with well-established antiproliferative properties [21, 22], was also examined for its potential to prevent $\mathrm{NH}$. The efficacy of sunitinib in inhibiting growth factor-stimulated proliferation was first examined in cultured SMCs and ECs, and then tested in an ex vivo perfused organ culture model using explanted whole porcine jugular vein segments. This ex vivo system enables us to recapitulate the pathological hemodynamic parameters occurring at the venous anastomosis in vivo, such as very low or very high WSS, with the additional advantage that it can be utilized to efficiently test pathogenic mechanisms and drugs under these and other specific isolated conditions. Whole-vessel segments retain the vessel wall architecture as well as cell-cell and cell-extracellular matrix interactions that are more relevant than primary monolayer cell cultures to the in vivo environment.

\section{Materials and Methods}

\section{Materials}

All culture reagents were purchased from Cascade Biologics (Portland, Oreg., USA) except for fetal calf serum (FCS), which was purchased from Atlanta Biologicals (Lawrenceville, Ga., USA). Sunitinib maleate was provided by Pfizer Inc. (New York, N.Y., USA). Recombinant human PDGF-BB and human VEGF 165 were purchased from R\&D Systems (Minneapolis, Minn., USA). Antibodies against PDGF-B chain, VEGF, PDGFR- $\alpha$ and VEGFR-2 were purchased from Thermo Scientific (Fremont, Calif., USA). Antibodies against von Willebrand factor (vWF) and Ki-67 were purchased from DAKO Pharmaceuticals (Carpinteria, Calif., USA). Anti-smooth-muscle a-actin antibody was purchased from Sigma (St. Louis, Mo., USA) and anti-glyceraldehyde-3-phosphate dehydrogenase (GAPDH) antibody was purchased from Abcam (Cambridge, Mass., USA). Secondary antibodies conjugated to horseradish peroxidase (HRP) were purchased from Santa Cruz Biotechnology (Santa Cruz, Calif., USA). All other antibodies were obtained from Cell Signaling Technologies (Danvers, Mass., USA).

\section{Porcine Model of AVG Stenosis}

All animal procedures were performed in accordance with a protocol that was approved by the Institutional Animal Care and Use Committees at the Veterans Affairs, Salt Lake City Health Care System, and the University of Utah. Female Yorkshire-cross domestic pigs (Sigma Livestock, Salt Lake City, Utah, USA) weighing approximately $30 \mathrm{~kg}$ were implanted with a spiral-reinforced polytetrafluoroethylene graft (C.R. Bard, Murray Hill, N.J., USA) unilaterally between the common carotid artery and the ipsilateral external jugular vein (EJV) as we have described previously [23, 24]. Animals were euthanized at the indicated time points, and the AVG and adjoining blood vessels were retrieved en bloc.

\section{Histology and Morphometry at Venous Anastomosis in the}

Porcine AVG Model

Explanted EJV segments were perfusion-fixed in formalin. Paraffin-embedded tissue cross sections from the center of the venous anastomosis were stained with elastic Van Gieson's stain (Accustain Elastic Stain, Sigma). The NH index was calculated as the ratio of the $\mathrm{NH}$ area to the combined area of the graft and media, as previously described [25]. Tissue sections from the same anastomotic region were also immunostained for the nuclear proliferation marker, Ki-67, and for the EC marker, vWF. The proliferation index (PI) was calculated as the ratio of the number of Ki67 -positive cells relative to the number of all cells in the same area, as described previously [6]. Direct manual counting of the vWFpositive neovessels in the $\mathrm{NH}$ and the adventitia in a given image field (i.e. neovessel density) was performed separately by 3 independent observers under light microscopy at a $\times 20$ magnification. Tissue sections from the same anastomotic region were also subjected to immunohistochemistry using antibodies against VEGF, VEGFR-2, PDGF-B and PDGFR- $\alpha$. 


\section{Cell Culture}

Primary human aortic SMCs (HASMCs), human saphenous vein SMCs (HVSMCs) and human umbilical vein ECs (HUVECs) were obtained from Cambrex (Chicago, Ill., USA). SMCs were maintained in Medium 231 supplemented with 10\% FCS. ECs were grown in Medium 200 prepared with growth supplements. Cells at passages 3-7 were used.

\section{In vitro Proliferation Assays}

HASMCs, HVSMCs and HUVECs were seeded at a density of $5 \times 10^{3}$ cells/well and cultured to approximately $70 \%$ confluence. Before each experiment, cells were rendered quiescent by incubating for $24 \mathrm{~h}$ with their respective basal media containing $0.5 \%$ FCS but no additional growth factors. Cells were then pretreated with various concentrations of sunitinib for $1 \mathrm{~h}$, followed by stimulation with either PDGF-BB (50 ng/ml) or VEGF $165(50 \mathrm{ng} / \mathrm{ml})$ for SMCs and ECs, respectively. After $48 \mathrm{~h}$, DNA synthesis was assessed by 5-bromo-2'-deoxyuridine (BrdU) incorporation (Roche Applied Science, Indianapolis, Ind., USA). At least 6 replicate experiments were analyzed for each sunitinib concentration for both SMCs and HUVECs.

\section{In vitro Migration Assays}

A suspension of $5 \times 10^{4}$ HASMC was loaded into the upper migration chamber of the InnoCyte ${ }^{\mathrm{TM}}$ Cell Migration Assay (Calbiochem, San Diego, Calif., USA) that contained media with $0.5 \%$ FCS but no additional growth factors. Cells were preincubated with various concentrations of sunitinib added to the media in both the upper and lower chambers for $1 \mathrm{~h}$, and then PDGF-BB (50 ng/ml) was added to the lower chamber. Cells were allowed to migrate through the porous membrane towards the lower chamber for $4 \mathrm{~h}$. Finally, the migrated cells that attached at the lowerchamber side of the membrane were dislodged and fluorescencelabeled with calcein AM, followed by quantification at $485 \mathrm{~nm}$. At least 3 replicate experiments were analyzed for each sunitinib concentration.

\section{Western Blotting}

Quiescent HASMCs were pre-exposed to various concentrations of sunitinib for $1 \mathrm{~h}$, then stimulated with PDGF-BB (50 ng/ $\mathrm{ml}$ ) for $10 \mathrm{~min}$ to determine early changes in signaling protein phosphorylation, for $24 \mathrm{~h}$ to assess changes in cell-cycle regulatory protein expression and for $6 \mathrm{~h}$ to determine the level of phosphorylated p53. As a positive control for apoptosis, cells were treated with $1 \mathrm{~mm}$ hydrogen peroxide for $6 \mathrm{~h}$ to induce the phosphorylation of p53. Cell lysates were prepared by washing cells with icecold PBS containing $150 \mathrm{~mm} \mathrm{NaCl}, 10 \mathrm{~mm}$ HEPES, 0.6\% NP-40 ( $\mathrm{pH}$ 7.9) and protease inhibitors, followed by incubation on ice for $30 \mathrm{~min}$, then centrifugation at $10,000 \mathrm{~g}$ for $10 \mathrm{~min}$. Protein concentrations were determined using the BCA protein assay (Pierce Chemical, Rockford, Ill., USA). Equal amounts of protein were loaded in each well on precast $4-20 \%$ gradient gels and subjected to SDS-PAGE. After transfer of proteins to nitrocellulose membranes for immunoblotting, the membranes were incubated with primary antibodies overnight at $4^{\circ} \mathrm{C}$, followed by HRP-conjugated secondary antibody incubation for $1 \mathrm{~h}$ at room temperature. Chemiluminescent detection of antibodies was conducted according to the manufacturer's protocol. Anti-GAPDH antibody was purchased from Abcam. All other antibodies were obtained from Cell Signaling Technologies.

\section{Ex vivo Perfused Vein Culture and Analysis}

From the same pigs that had been used to create AVG, segments of the internal jugular vein (IJV) from the contralateral side were harvested at euthanasia for ex vivo organ culture using sterile techniques. An ex vivo perfusion system, similar to that described [26-28], with modifications of the vessel chamber and the longterm application of laminar flow with various WSS values, was used. Briefly, explanted IJV segments were suspended at their in vivo length $(3-5 \mathrm{~cm})$ between 2 stainless steel connectors using surgical sutures, and bathed in a vessel chamber filled with Dulbecco's modified eagle medium (DMEM) supplemented with 30\% FCS and antibiotics but no additional growth factors. Vein segments were perfused with the oxygenated DMEM media (same as in the vessel chamber) that was recirculated at a laminar, constant volumetric flow rate to generate specific calculated WSS values at the lumen-vessel wall interface. Volumetric flow rate was measured manually through a flow valve positioned immediately downstream of the vessel chamber. Vein segments were cultured for 12 consecutive days with media flowing continuously $(n=6)$. Fresh media was supplied every $2-3$ days. In the sunitinib-treated veins $(n=3)$, sunitinib was added to the circulating media as well as to the media that filled the vessel chamber on the second day of ex vivo culture. The delay in sunitinib administration was designed to allow the vessels to recover from the explantation procedure. Sunitinib was also added to the fresh replacement media to maintain a constant media drug concentration of $100 \mathrm{nM}$ throughout the duration of the experiment.

WSS was calculated using the following equation: WSS = $(4 \mu \mathrm{Q}) /\left(\pi \mathrm{r}^{3}\right)$, where $\mu$ is the viscosity of the culture media containing serum $(\mu=0.01$ Poise), $Q$ is the volumetric flow rate through the vessel adjusted to generate the desired WSS, and $r$ is the inner radius of the vessel lumen measured at the time of harvest. The WSS inside the vessels was maintained at $<1 \mathrm{dyn} / \mathrm{cm}^{2}$ at the beginning of culture $(n=5)$, a value that is considered nonphysiologically low for the normal vein. One of the untreated control IJV segments had a small inner radius, such that we were unable to generate an initial low WSS value; therefore, this vein segment was subjected to a WSS of $>50 \mathrm{dyn} / \mathrm{cm}^{2}$ which is nonphysiologically high for the normal vein.

Explanted IJV segments were formalin-fixed at the end of each perfusion experiment by directly perfusing formalin into the lumen through the metal tubes and immersing the entire vessel in formalin for 24-48 h. Paraffin-embedded cross-sections were stained with either hematoxylin/eosin (Poly Scientific, Bay Shore, N.Y., USA) or Van Gieson's stain. The cross-sectional surface areas of various vessel wall regions were determined using planimetry under light microscopy, and were quantified using the NIH ImageJ software. The results were used to calculate the intima-tomedia area $(\mathrm{I} / \mathrm{M})$ ratio and the intima-to-lumen area $(\mathrm{I} / \mathrm{L})$ ratio. In immunohistochemistry analysis, SMCs and/or myofibroblasts were identified by positive fluorescence immunostaining with anti-smooth-muscle $\alpha$-actin, while apoptotic and proliferating cells were identified by positive staining with anti-cleaved caspase- 3 and anti-Ki-67 antibodies, respectively. ECs were identified by positive immunostaining with anti-vWF antibody. Immunostained proteins were visualized using confocal microscopy.

For comparison, some IJV segments were kept in the static condition for 12 days. In these static experiments, vein segments of about $1-2 \mathrm{~cm}$ in length were cut longitudinally after harvest from the animal to expose the lumen, pinned onto a sterile mesh, and 


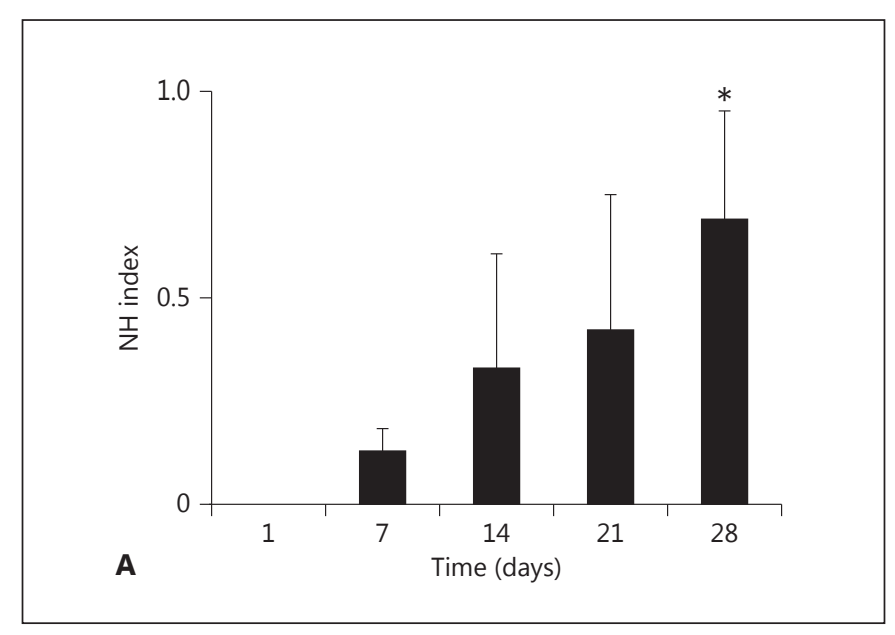

Fig. 1. Time course of $\mathrm{NH}$ development, neovessel density and PI at the venous anastomosis in a porcine AVG model. A NH index at the venous anastomosis was calculated as the ratio of $\mathrm{NH}$ crosssectional area to the combined area of the graft and media in tissues collected at various time points $(\mathrm{n}=2,3,3,7$ and 5 animals at days $1,7,14,21$ and 28 , respectively). ${ }^{*} \mathrm{p}<0.05$ versus day 1 . B, C Anastomotic tissue sections were immunostained to detect neovessels and proliferating cells, using antibodies against vWF and Ki-67, respectively, within the $\mathrm{NH}(\mathbf{B})$ and the adventitia (C). PI was determined by dividing the number of Ki-67-positive nuclei by the total number of nuclei in the image field ( $n=4$ animals for each time point). ${ }^{*} \mathrm{p}<0.05$ versus day 1 for neovessel density; ${ }^{*} \mathrm{p}<0.001$ versus day 1 for PI. In all panels, each data point represents the mean and standard deviation.

cultured in DMEM containing 30\% FCS in a tissue culture dish. Formalin-fixation, paraffin-embedding and Van Gieson's stain were performed as described above for the perfused veins.

\section{Data Analysis}

Results are reported as mean \pm standard deviation. Two-tailed Student's t test and one-way analysis of variance (ANOVA) with Tukey's post hoc test were performed using GraphPad Prism (GraphPad Software, San Diego, Calif., USA). Statistically significant results are defined as $\mathrm{p}<0.05$. $\mathrm{IC}_{50}$ was estimated using GraphPad Prism's built-in non-linear regression (least squares) curve fitting.

\section{Results}

\section{NH in Porcine AVG Model}

In the porcine model of AVG established in our laboratory, significant stenosis is usually present within


4 weeks after the graft placement $[6,23]$. Here, we conducted a time course analysis to delineate the temporal relationships between $\mathrm{NH}$, angiogenesis and cell proliferation in tissue sections obtained from the venous anastomosis. Progression of the $\mathrm{NH}$ index (fig. 1A), calculated as the ratio of the $\mathrm{NH}$ area to the combined area of the graft and media, exhibited the same trend as the time-dependent increase in angiogenesis within the $\mathrm{NH}$ lesions (fig. 1B). Specifically, both the $\mathrm{NH}$ index and angiogenesis in the $\mathrm{NH}$ lesions were increased at postoperative day 7 whereas the PI in the NH lesions was significantly increased after day 14 . This time lag is consistent with the notion that angiogenesis is essential for further $\mathrm{NH}$ development by supplying oxygen and nutrients to proliferating cells. Interestingly, the neovessel density within the adventitia immediately increased after AVG placement, but was followed by a 
Fig. 2. Enhanced expression of VEGF, PDGF and their cognate receptors at the venous anastomosis in a porcine AVG model. Expression of VEGF, VEGFR-2, PDGF-B and PDGFR- $\alpha$ in fresh EJV (left column) and in the venous anastomotic tissues at 14 days (middle column) and 28 days (right column) after AVG placement was assessed by immunohistochemistry. A rust-brown color indicates positive staining for the indicated proteins. Blue structures are hematoxylin-stained nuclei (colors refer to the online version only). When compared to fresh EJV, venous anastomotic tissues had early (14 days) robust upregulated expression of these growth factors and their cognate receptors as well as sustained (28 days) overexpression of both growth factor receptors. Stained sections were assessed. $\times 20$. The scale bar in the top left panel applies to all panels in this figure. $\mathrm{L}=$ lumen.


Day 28
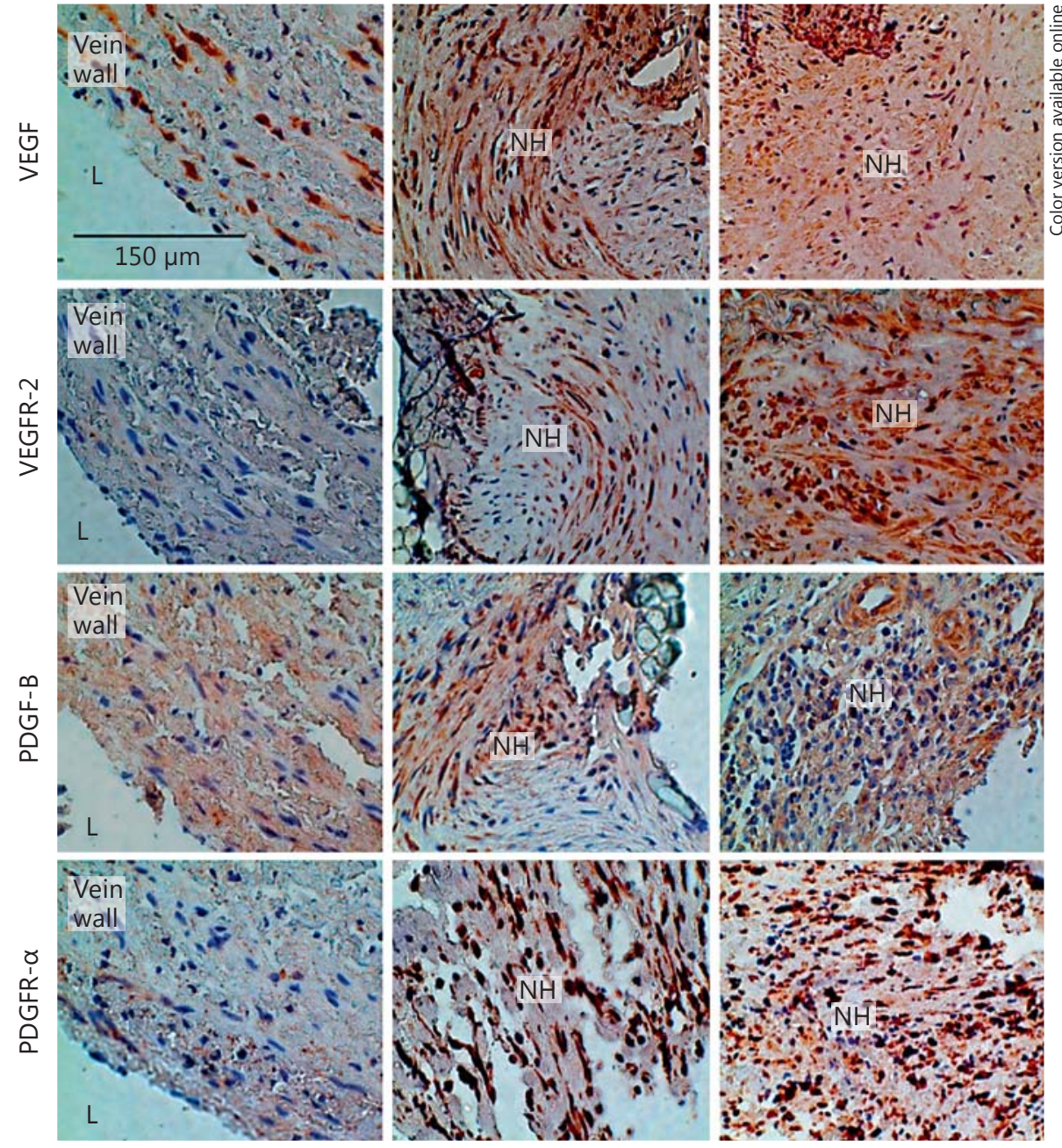

sharp decrease after day 7 (fig. 1C). The adventitia showed the highest PI at early time periods, and after day 7 the changes in adventitial PI largely paralleled the changes in neovessel density. This temporal profile of proliferating cells in the adventitia was different from that in the $\mathrm{NH}$ and is consistent with the notion that an early event in $\mathrm{NH}$ development is the transformation and proliferation of adventitial myofibroblasts which subsequently migrate into the $\mathrm{NH}$ and contribute to $\mathrm{NH}$ formation $[8,12]$. Similar data on cell proliferation and angiogenesis occurring in the adventitia and in the $\mathrm{NH}$ lesions at selected time points after the graft placement, determined by Ki-67 and vWF immunostaining, respectively, were reported previously by our group [6].

\section{Enhanced Expression of Pro-NH Factors in the Porcine AVG Model}

Expression of VEGF and PDGF has been reported to be prominent in the venous $\mathrm{NH}$ lesions of specimens obtained from patients with failed AVG [11]. We therefore investigated whether these mediators of proliferation, migration and angiogenesis and their receptors were expressed at the venous anastomosis in our porcine AVG model. Figure 2 shows that in the NH lesions, VEGF, PDGF-B and their respective receptors, VEGFR-2 and PDGFR- $\alpha$, stained intensely at 14 days after AVG placement, compared to the control EJV. Moreover, the expression of these growth factors and their cognate receptors remained high at 28 days postoperatively. Interestingly, we observed that VEGFR-2 expression was diffusely distributed across the $\mathrm{NH}$ area, suggesting that 




Fig. 3. Sunitinib inhibits PDGF-BB-induced proliferation of SMCs and $\mathrm{VEGF}_{165}$-induced proliferation of ECs in vitro. A HASMCs and HVSMCs were preincubated with the indicated concentrations of sunitinib for $1 \mathrm{~h}$ before exposure to PDGF-BB (50 ng/ml) for $48 \mathrm{~h}$. B HUVECs were preincubated with the indicated concentrations of sunitinib for $1 \mathrm{~h}$ before exposure to $\operatorname{VEGF}_{165}(50 \mathrm{ng} / \mathrm{ml})$ for $48 \mathrm{~h}$. Proliferation was assessed using the bromodeoxyuridine incorporation assay. At least 6 replicate experiments were analyzed for each sunitinib concentration. ${ }^{*} \mathrm{p}<0.001$ versus PDGF-stimulated no-sunitinib control HASMCs, PDGF-stimulated no-sunitinib control HVSMCs or VEGF-stimulated no-sunitinib control HUVECs; ${ }^{*} \mathrm{p}<0.01$ versus PDGF-stimulated no-sunitinib control HVSMCs.

under pathologic conditions, upregulation of this receptor type is also prominent in SMCs. In general, SMCs express low levels of VEGFR-2 [29], but certain stimuli related to $\mathrm{NH}$ pathogenesis (e.g. hypoxia) are thought to promote the expression of VEGFR in SMCs [30, 31]. These observations are consistent with the notion that VEGF, PDGF and their receptors play key roles in both the early development and sustained progression of $\mathrm{NH}$.

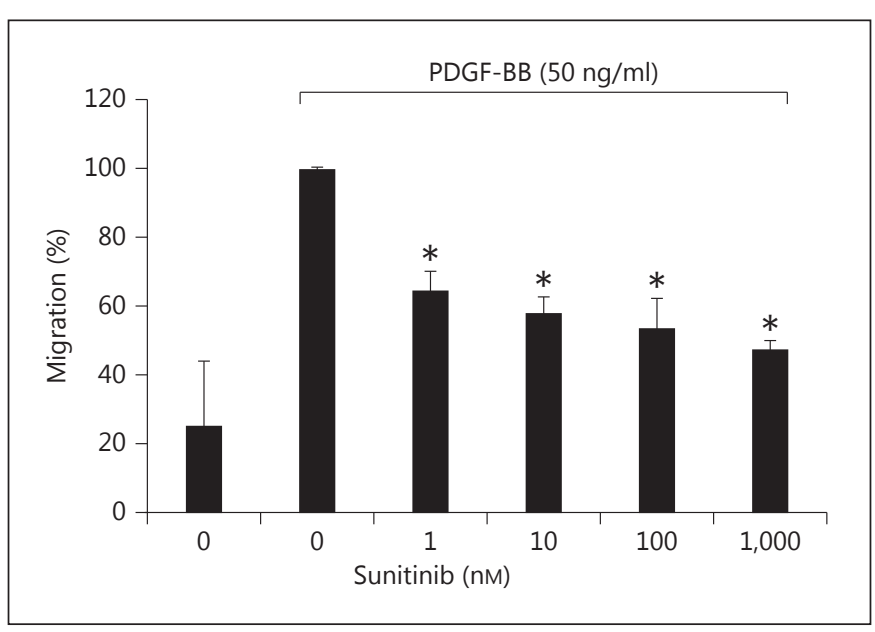

Fig. 4. Sunitinib inhibits PDGF-BB-induced migration of SMCs in vitro. HASMCs in a migration assay chamber were preincubated with the indicated concentrations of sunitinib for $1 \mathrm{~h}$, and then stimulated with $50 \mathrm{ng} / \mathrm{ml}$ of PDGF-BB. HASMCs were allowed to migrate for $4 \mathrm{~h}$, and the migrated cells were fluorescence-labeled and counted. At least 3 replicate experiments were analyzed for each sunitinib concentration. ${ }^{*} \mathrm{p}<0.001$ versus PDGF-stimulated no-sunitinib control.

Accordingly, we examined the effects of sunitinib, a multitarget RTK inhibitor of VEGFR and PDGFR, on proliferation, migration and intracellular signaling in cell cultures and in an ex vivo perfused-vein model.

\section{Sunitinib Inhibits Growth Factor-Induced}

Proliferation of Human Vascular Cells

Primary HASMCs and HVSMCs were stimulated with $50 \mathrm{ng} / \mathrm{ml}$ of PDGF-BB for $48 \mathrm{~h}$, after pretreatment with various concentrations of sunitinib. Sunitinib inhibited the PDGF-BB-induced proliferation of SMCs in a dosedependent manner, with complete inhibition occurring at approximately $100 \mathrm{nM}$ (fig. 3A). The mean $\mathrm{IC}_{50}$ was approximately $10 \pm 3 \mathrm{nM}$ for HASMCs and $40 \pm 3 \mathrm{nM}$ for HVSMCs. Sunitinib almost completely inhibited VEGFinduced proliferation of HUVECs at concentrations $\geq 10$ $\mathrm{nM}$ (fig. 3B), with $\mathrm{IC}_{50}$ of approximately $8 \pm 4 \mathrm{nM}$. Gross cytotoxicity was not apparent under these conditions, as assessed by morphologic examination, and was manifested only at concentrations $>10,000 \mathrm{nM}$ (data not shown).

\section{Sunitinib Inhibits PDGF-BB-Induced Migration of Human Vascular SMCs}

Because NH initiation and development are attributable, at least in part, to the migration of cells, including medial SMCs and presumably adventitial fibroblasts/ 


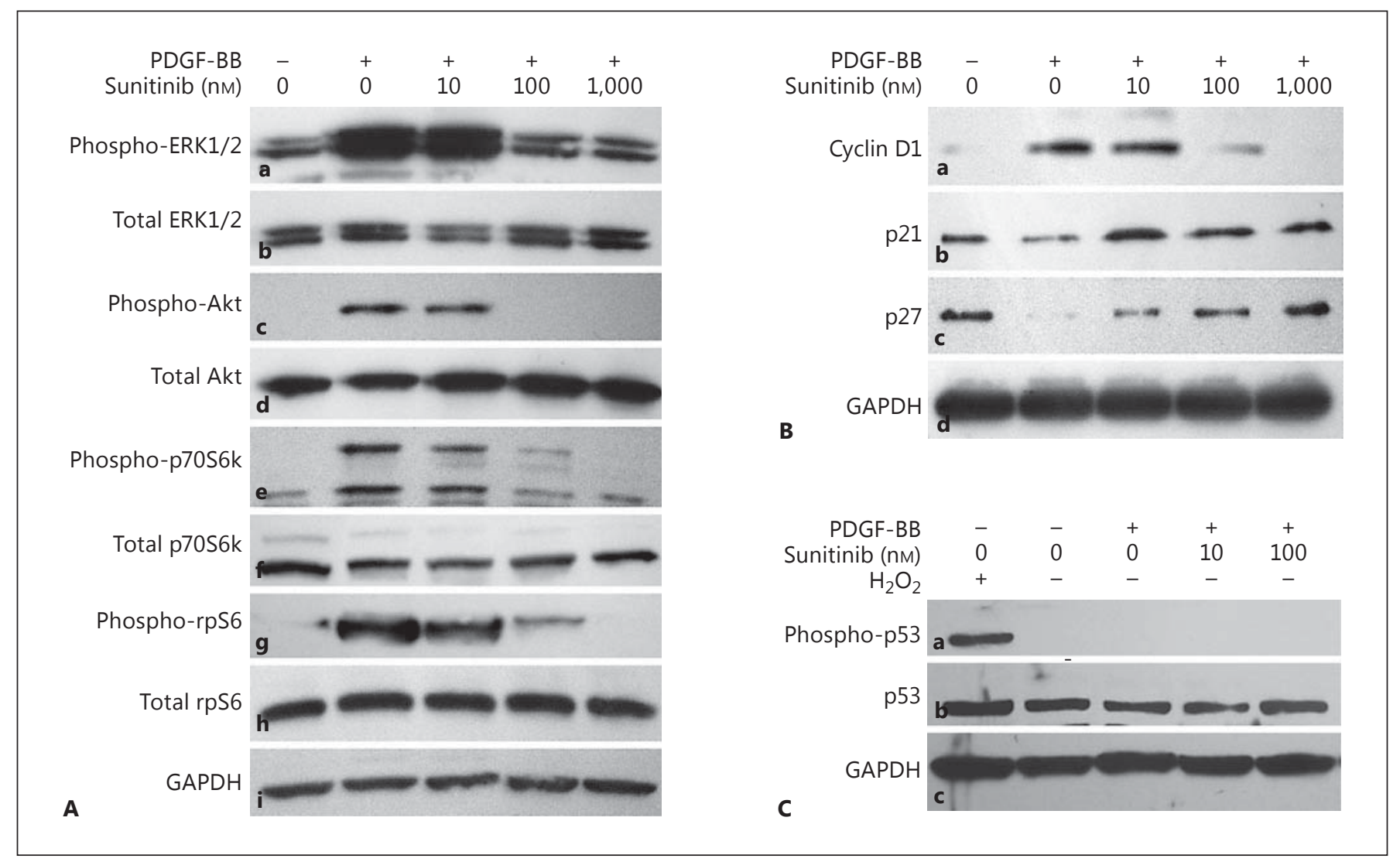

Fig. 5. Sunitinib inhibits PDGF-BB-induced changes in phosphorylation of MAPK and PI3K/AKT signaling proteins and expression of cell-cycle regulatory proteins of HASMCs in vitro. A Phosphorylation of the MAPK and the PI3K/Akt pathway after exposure of HASMCs to PDGF-BB for $10 \mathrm{~min}$, in the absence or presence of sunitinib, is shown: ERK1/2 (a), Akt (c), p70S6k (e) and rpS6 (g). Levels of total ERK1/2 (b), Akt (d), p70S6k (f) and rpS6 (h) proteins are shown. GAPDH was used as a loading control (i). B Levels of various cell-cycle regulatory proteins after exposure

myofibroblasts, into the growing $\mathrm{NH}[6,8,12]$, we investigated whether sunitinib also attenuated the migration of HASMCs. Sunitinib inhibited the SMC migration stimulated by $50 \mathrm{ng} / \mathrm{ml}$ of PDGF-BB in a dose-dependent manner, with approximately $45 \%$ inhibition observed at $1 \mathrm{nM}$ (fig. 4). Higher concentrations of sunitinib (100-1,000 nM) did not further inhibit SMC migration.

\section{Effects of Sunitinib on Signaling Proteins and Cell-}

Cycle Regulatory Proteins in Human Vascular SMCs

As reported previously by others [32, 33], PDGF-BB at $50 \mathrm{ng} / \mathrm{ml}$ activated the MAPK and PI3K/Akt pathways, as indicated by the robust phosphorylation of ERK1/2, Akt, p70S6k and rpS6 (fig. 5A). The down- of HASMCs to PDGF-BB for $24 \mathrm{~h}$, in the absence or presence of sunitinib, are shown: cyclin D1 (a), p21 (b) and p27 (c). GAPDH was used as a loading control (d). C The toxicity of sunitinib at concentrations that inhibited the PDGF-stimulated signaling pathways and cell-cycle regulatory proteins was evaluated by examining the phosphorylation of the p53 protein (a). Hydrogen peroxide-induced apoptosis served as the positive control. Levels of total p53 are shown (b). GAPDH was used as a loading control (c).

stream proteins of these pathways, p70S6k and rpS6, regulate translation of mRNAs and the expression of proteins important for proliferation [34]. We found that sunitinib inhibited the phosphorylation of these proteins in a dose-dependent manner. PDGF-induced phosphorylation of ERK1/2 and Akt was almost completely abolished by $100 \mathrm{nM}$ sunitinib, the same concentration that completely inhibited SMC proliferation, as shown in figure $3 \mathrm{~A}$. Sunitinib also inhibited, in a dosedependent manner, the effects of PDGF-BB on the expression of the key cell-cycle regulatory proteins, cyclin D1, p21 and p27. At $100 \mathrm{nM}$ sunitinib, the PDGF-induced expression of cyclin D1, a cyclin-dependent kinase activator and one of the earliest mitogenic regula- 


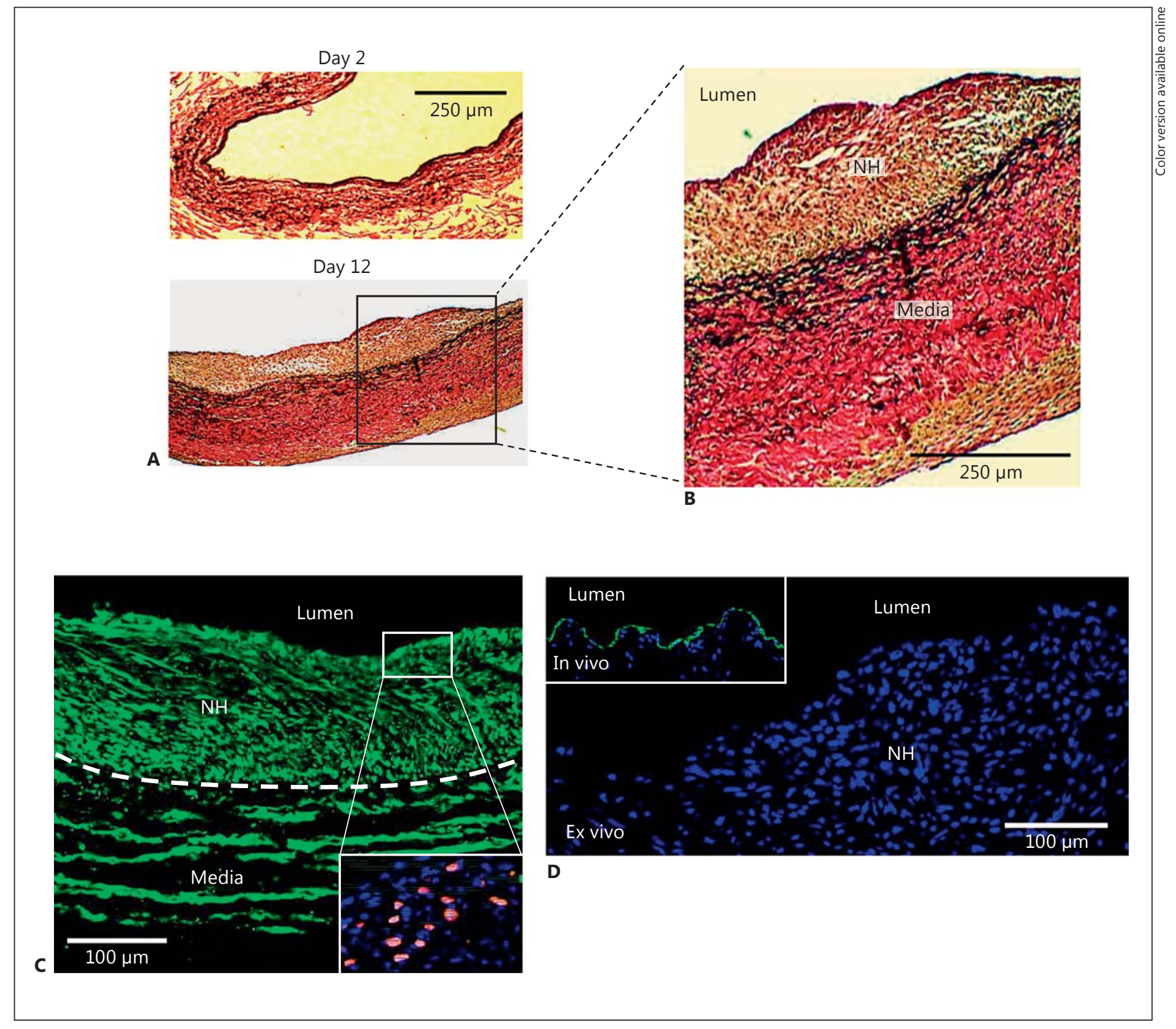

Fig. 6. NH formation in porcine IJV segments maintained in an ex vivo perfused culture. Porcine IJV segments were exposed to nonphysiological WSS in a perfused culture system for 12 days $(n=3)$. Cross-sections were stained with Van Gieson's stain (elastic fibers and nuclei appear black; collagen appears red). Representative cross-sectional views are shown (colors refer to the online version only). A, B IJV segment harvested after 2 days of perfused culture shows no NH lesions. Prominent NH lesions were observed after 12 days of perfused culture. C Tissue sections were coimmunostained for smooth-muscle $\alpha$-actin (appearing green) and Ki-67 (appearing pink in the insert) and examined under confocal mi- croscopy. $\times 20$. Blue staining denotes cell nuclei, and the dashed line demarcates the $\mathrm{NH}$ lesion from the media. Cells constituting the lesions costained positive for $\alpha$-actin and Ki-67. D NH lesions formed at the venous anastomosis of an EJV in vivo and in ex vivo perfused vein segments were examined for ECs. Tissue sections were assessed. $\times 20$. Blue staining denotes cell nuclei. $\mathrm{NH}$ lesions formed in EJV 4 weeks after graft implantation had an intact endothelium that stained positive for vWF (appears green in the insert). NH lesions formed in IJV after 12 days of ex vivo perfused culture were negative for vWF staining. 


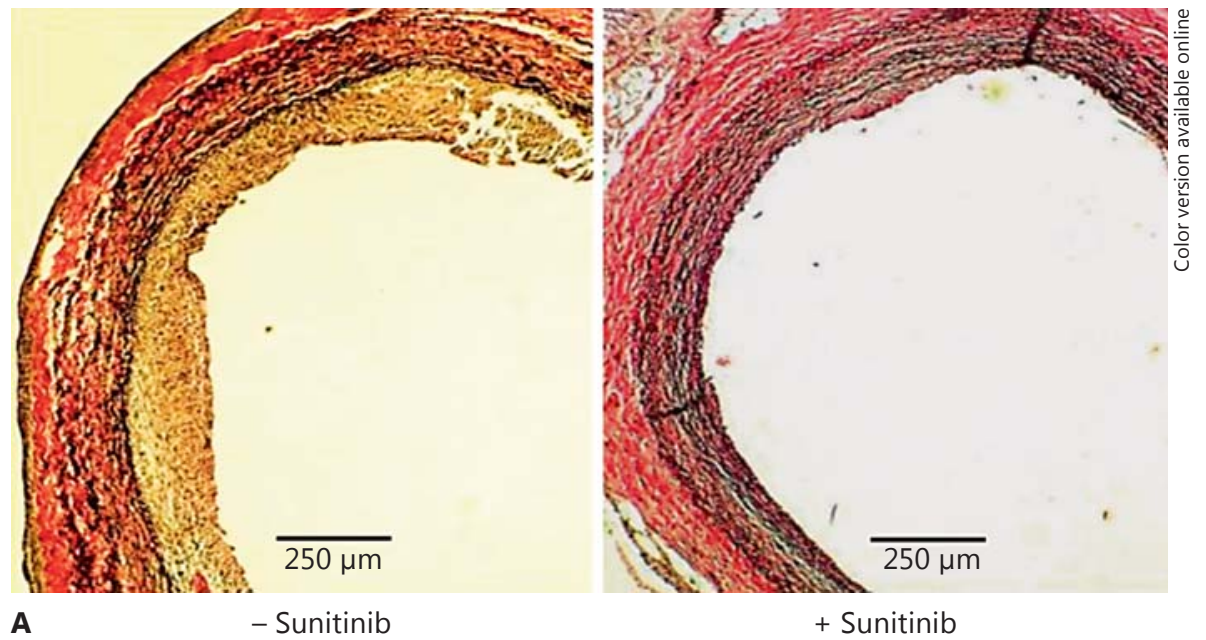

Fig. 7. Sunitinib inhibits $\mathrm{NH}$ formation in porcine IJV segments maintained in an ex vivo perfused culture. A Representative histological images of the tissue cross-sections revealed healthy vein walls in both untreated control and sunitinib (100 nM)treated vein segments perfused for 12 days. Van Gieson's stain. $\times 10$. B The I/M ratio decreased from $0.38 \pm 0.24$ in the untreated vessels $(n=3)$ to $0.13 \pm 0.05$ in the sunitinib-treated vessels $(n=3 ; p<0.15)$. The $\mathrm{I} / \mathrm{L}$ ratio decreased from $0.45 \pm 0.25$ to 0.04 $\pm 0.02(* \mathrm{p}<0.05)$.

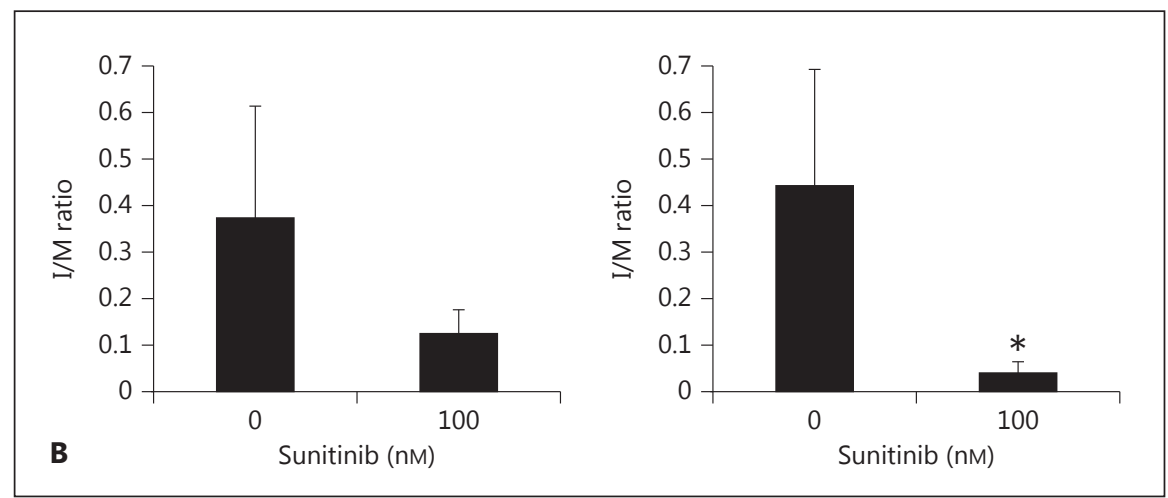

tors of cell-cycle progression, was nearly completely inhibited (fig. 5B). In contrast, the expression of p21 and p27, cyclin-dependent kinase inhibitors that function as antimitogenic regulators, were potently decreased by PDGF-BB stimulation, and this effect was reversed by concentrations of sunitinib as low as $10 \mathrm{nM}$ (fig. 5B). Densitometric analyses of images are shown in online supplementary figure 1 (for all online suppl. material, see www.karger.com/doi/10.1159/000442977). These observations are consistent with the notion that sunitinib inhibits the action of PDGF-BB by suppressing the expression of promitotic regulatory proteins and enhancing the expression of cell-cycle progression inhibitors in vascular SMCs. Phosphorylation of p53, an event that promotes apoptotic cell death, was examined after sunitinib treatment, to assess the toxicity of this drug at pharmacologically relevant concentrations. Sunitinib, even at the maximal dose used to inhibit proliferation (100 nM) failed to induce apoptosis in cultured HASMCs (fig. 5C).
Sunitinib Inhibits Venous NH Formation in ex vivo Perfused Vein Culture

Explanted porcine IJV segments were perfused ex vivo under defined nonphysiological laminar-flow conditions for up to 12 days, or kept in a static-flow condition for comparison. All vein segments cultured ex vivo appeared intact and patent after 12 days. Histological examination showed significant $\mathrm{NH}$ formation in the perfused vein segments at 12 days in culture (fig. 6A, B). However, vein segments in static culture did not develop NH (data not shown), suggesting that perfusion per se is an important promoter of $\mathrm{NH}$ development. Cells in the $\mathrm{NH}$ lesions appeared disorganized, stained positive for smooth-muscle $\alpha$-actin, and had elevated levels of proliferation as determined by Ki-67 immunostaining (fig. 6C). These histological features are similar to those observed in the $\mathrm{NH}$ lesions in our porcine model in vivo. However, in contrast to the in vivo lesions, we did not detect an intact endothelium or any neovessels in the $\mathrm{NH}$ lesions (fig. 6D).

Sunitinib (100 nM) markedly inhibited NH lesion formation in the vein segments perfused ex vivo (fig. 7A). 
Fig. 8. Low level of apoptosis and cell proliferation in sunitinib-treated vein segments. Apoptotic cells appear bright yellow in representative tissue sections, while blue staining denotes cell nuclei, and the dashed line demarcates the $\mathrm{NH}$ lesion from the media (colors refer to the online version only). Both untreated control (A) and sunitinib-treated (B) vein segments perfused for 12 days showed low levels of apoptosis. Proliferating cells (appearing bright yellow) in the neointima in untreated control (C) and sunitinib-treated (D) vein segments perfused for 12 days were examined in representative tissue sections. Blue staining denotes cell nuclei. Sunitinib-treated vein samples had less proliferating cells than untreated vein samples.


The mean I/M ratio decreased in sunitinib-treated vein segments, although this difference did not reach statistical significance $(0.38 \pm 0.24$ vs. $0.13 \pm 0.05 ; \mathrm{n}=3$ each; $\mathrm{p}<0.2$; fig. 7B). The mean I/L ratio, which takes into consideration variations in the lumen diameters, was, however, significantly decreased $(0.45 \pm 0.25$ vs. $0.04 \pm 0.02 ; n=3$ each; $\mathrm{p}<0.05$; fig. 7B). Anti-cleaved caspase- 3 and anti-Ki-67 antibodies were used to identify apoptotic and proliferating cells, respectively, in the perfused vein samples. Similarly low levels of apoptotic cell death were seen in the sunitinib-treated and untreated vein samples (fig. 8A, B), indicating that the inhibitory effect of sunitinib on $\mathrm{NH}$ formation was not the result of apoptosis. Sunitinib-treated vein samples had fewer proliferating cells than untreated vein samples ( 2 and $9 \%$ of $\mathrm{Ki}-67$-positive nuclei in the representative images in sunitinib-treated and control veins, respectively), consistent with the notion that sunitinib prevents $\mathrm{NH}$ formation through inhibiting cell proliferation (fig. 8C, D). Expression of VEGF and PDGF-B in IJV tissues cultured under flow for 12 days without or with sunitinib was assessed by immunohistochemistry and shown in figure 9. Sunitinib-treated vein samples expressed less VEGF and PDGF-B than untreated vein samples.

\section{Discussion}

The purpose of our investigation was to utilize a variety of model systems to assess the properties of sunitinib, which will allow us to better understand the underlying pathophysiology and explore potential pharmacotherapy to prevent NH. In this study, the mechanism of sunitinib's action was examined in cultured arterial and venous SMCs stimulated with PDGF, and in ECs stimulated with VEGF. The selection of sunitinib, an angiogenesis inhibitor, was motivated by the presence of neovessels (fig. 1) and the expression of the growth factors PDGF, VEGF and their respective receptors (fig. 2) in the juxta-anastomotic $\mathrm{NH}$ lesions in our porcine AVG model. A recent study by Ishii 
Fig. 9. Sunitinib inhibits the enhanced expression of VEGF and PDGF in the veins cultured ex vivo. Expression of VEGF and PDGF-B in fresh (Day 0, D0) EJV (left column) and in the IJV tissues cultured under flow for 12 days (D12) without sunitinib (middle column) and with sunitinib (right column) was assessed by immunohistochemistry. A rust-brown color indicates positive staining for the indicated proteins. Blue structures are hematoxylin-stained nuclei (colors refer to the online version only). Sunitinib-treated vein samples had less VEGF and PDGF-B than untreated vein samples. $\mathrm{L}=$ lumen.

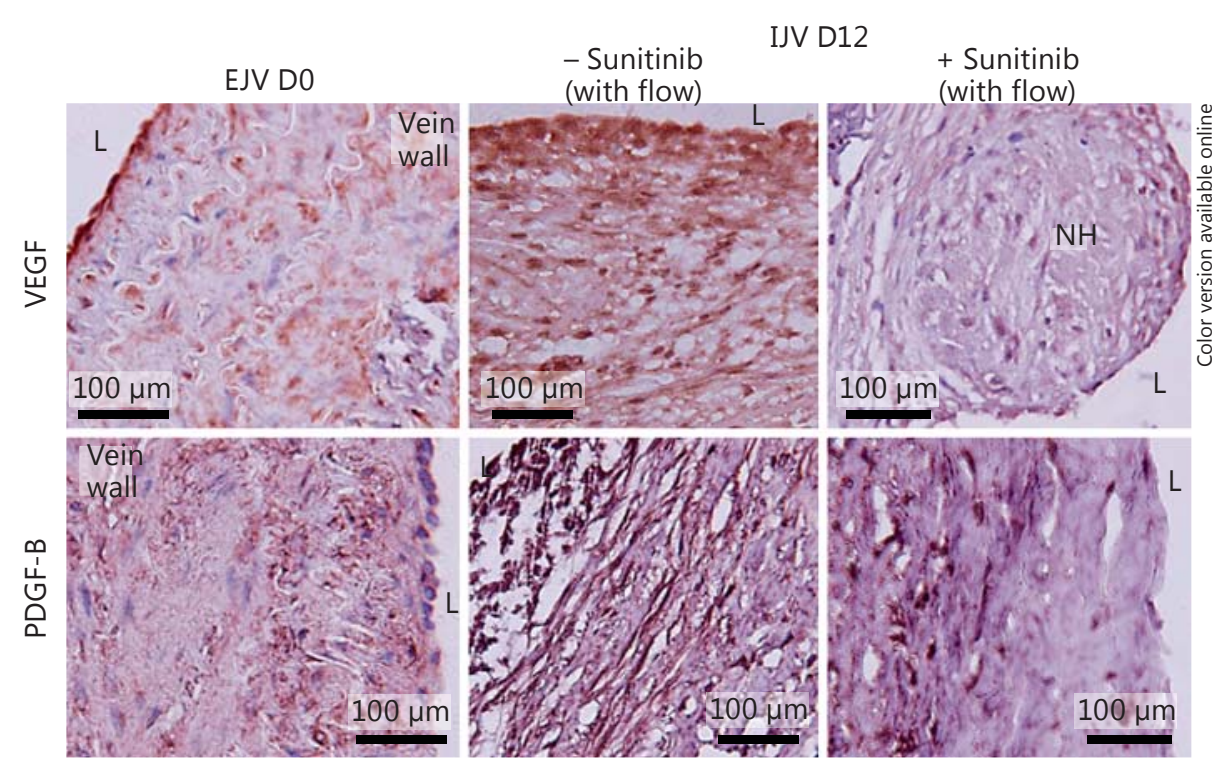

et al. [35] reported that sunitinib inhibited PDGF-induced DNA synthesis, proliferation and migration in cultured HASMCs, and inhibited $\mathrm{NH}$ formation in a rat model of balloon-injury of carotid arteries. We previously showed that there was a significant difference between cultured arterial and venous SMCs in their response to the PDGFR inhibitor imatinib [36]. Building on this knowledge, here, we investigated the effects of sunitinib on cultured HVSMCs, besides HASMCs, and on explanted porcine whole blood vessel segments cultured ex vivo under flow conditions. An important feature of the ex vivo culture system is that it incorporates a segment of vein, which is the most relevant vessel for studies on venous $\mathrm{NH}$ associated with AVG based on clinical observations and previous work in porcine models.

We demonstrated that sunitinib blocked signal transduction downstream of mitogenic RTKs by inhibiting the phosphorylation of key proteins in the MAPK and the PI3K/Akt pathways in cultured SMCs (fig. 5). These changes in signaling protein phosphorylation were accompanied by the reversal of changes in the expression of key cell-cycle regulatory proteins. The effects of sunitinib on the MAPK and PI3K/Akt pathways in vascular SMCs, and especially its effects on p70S6k and rpS6, have not been previously reported. Whether additional pro-NH intracellular pathways are activated in the presence of aberrant $\mathrm{NH}$-promoting conditions will need to be examined in future studies.

It has been proposed that multiple pathogenic factors contribute to NH development after AVG placement [3]. However, the localized nature of $\mathrm{NH}$ with strong predis- position at the venous anastomosis points toward abnormal blood flow as an important pathogenic factor because shunting of arterial blood flow exposes the vein to a highly aberrant hemodynamic environment. Previous biomechanics studies have shown that manipulation of certain hemodynamic parameters in the vein, such as hydrostatic pressure or WSS, can induce pathological vessel remodeling, including wall hypertrophy and $\mathrm{NH}$ development [26, 27]. In our study, we explored this concept using an ex vivo model system that reproduced the pathological WSS occurring at the venous anastomosis of AVG in vivo, and observed that aberrant WSS was indeed associated with $\mathrm{NH}$ formation in the explanted porcine vein segments (fig. 6). These ex vivo NH lesions resembled the lesions observed in vivo and were also comprised primarily of disorganized, proliferating cells that stained positive for smooth-muscle $\alpha$-actin $[6,23]$. Chronic exposure to low concentrations of sunitinib substantially attenuated $\mathrm{NH}$ formation in vein segments in this ex vivo perfused culture system. Of interest, past studies used human saphenous vein segments to demonstrate substantial $\mathrm{NH}$ formation under static culture conditions without perfusion [37,38], which we were unable to reproduce in our porcine jugular veins cultured statically. These earlier studies suggested that mechanical forces may not be necessary stimuli for intimal growth, at least in culture conditions that were adopted using human veins [37, 38]. However, a number of factors including species differences, the anatomical source of the veins and differences in culture methods could have contributed to the discrepant findings. Our re- 
sults agree with those reported by Gusic et al. [27] and Joddar et al. [28], in which minimal NH development was observed in porcine saphenous veins cultured under static culture conditions, in contrast to perfused veins.

In our ex vivo model, there was a loss of resident ECs in our cultured veins, which was similar to previous observations $[26,27]$ and occurred even in the absence of antiproliferative drugs. The EC loss was likely due to the tissue damage during vein explanting or the absence of critical factors that maintain EC viability in our culture system. In all of the static culture experiments that we conducted in parallel to the perfused experiments, none showed an intact endothelium (data not shown). Corroborating our observations, studies by Gusic et al. [27] reported the lack of an intact endothelium monolayer after culturing porcine vein segments for 7 days or longer under abnormal shear stress and/or pressure. Although we expect that improved explanting techniques may minimize this resident EC loss, it is also noteworthy that the role of damaged endothelium (and restoration of the endothelium) on $\mathrm{NH}$ pathogenesis is controversial in the current literature and has been the subject of persistent debate [39]. Future investigations are necessary to determine whether and how prevention of endothelium damage may affect the ex vivo culture model.

A notable advantage of the ex vivo perfused culture model is that it permits the investigation of explanted whole-vessel segments in well-defined hemodynamic environments that may cause $\mathrm{NH}$ in vivo. At the same time, the whole-vessel segment provides the opportunity for cell migration and cross-talk within the architectural framework of the native vessel that may be critical for vessel wall remodeling and $\mathrm{NH}$ development. Prominent features of $\mathrm{NH}$ were readily observed in these cultured vein segments (fig. 6), highlighting the relevance of this model to in vivo events. The requirement for only a small number of animals to provide the necessary blood vessel segments for these ex vivo experiments greatly reduced the costs. An additional advantage of our ex vivo perfusion system is that it is well suited to study the effect of other isolated factors, such as uremia, on the pathogenesis of NH. The study of uremia is of particular interest, since $\mathrm{NH}$ has been reported to be present in blood vessels of uremic patients even prior to the creation of a vascular access [40], and uremia appears to potentiate $\mathrm{NH}$ development in mouse and rat AV fistula models [41-43]. For example, uremic plasma, specific uremic toxins or isolated blood vessels from uremic animals or patients could be used in this ex vivo model to investigate the effects of uremia on $\mathrm{NH}$ development and to study potential anti-NH agents.

In conclusion, sunitinib was demonstrated to be effective in inhibiting several cellular signaling events associated with $\mathrm{NH}$ development in AVGs. Furthermore, sunitinib attenuated $\mathrm{NH}$ formation induced by nonphysiological mechanical cues in an ex vivo perfused organ culture system. The long-term efficacy and safety of sunitinib therapy in vivo require further evaluation.

\section{Acknowledgements}

This work was supported by NIH R01HL67646, the Veterans Affairs Merit Review Program and a grant from Pfizer, Inc. to A.K.C., and NIH R01DK100505 to Y.-T.S.

\section{Disclosure Statement}

Pfizer donated the sunitinib used in these studies.

\section{References}

1 Allon M, Robbin ML: Increasing arteriovenous fistulas in hemodialysis patients: problems and solutions. Kidney Int 2002;62:11091124.

2 Dember LM, Beck GJ, Allon M, Delmez JA, Dixon BS, Greenberg A, Himmelfarb J, Vazquez MA, Gassman JJ, Greene T, Radeva MK, Braden GL, Ikizler TA, Rocco MV, Davidson IJ, Kaufman JS, Meyers CM, Kusek JW, Feldman HI; Dialysis Access Consortium Study Group: Effect of clopidogrel on early failure of arteriovenous fistulas for hemodialysis: a randomized controlled trial. JAMA 2008;299: 2164-2171.

3 Li L, Terry CM, Shiu YT, Cheung AK: Neointimal hyperplasia associated with synthetic he-

RTK Inhibitor and Venous Hyperplasia in an ex vivo Model modialysis grafts. Kidney Int 2008;74:12471261.

4 Singh P, Robbin ML, Lockhart ME, Allon M: Clinically immature arteriovenous hemodialysis fistulas: effect of US on salvage. Radiology 2008;246:299-305.

5 Collins AJ, Foley RN, Chavers B, Gilbertson D, Herzog C, Johansen K, Kasiske B, Kutner N, Liu J, St Peter W, Guo H, Gustafson S, Heubner B, Lamb K, Li S, Li S, Peng Y, Qiu Y, Roberts T, Skeans M, Synder J, Solid C, Thompson B, Wang C, Weinhandl E, Zaun D, Arko C, Chen S, Daniels F, Ebben J, Frazier E, Hanzlik C, Johnson R, Sheets D, Wang X, Forrest B, Constantini E, Everson S, Eggers P, Agodoa L: United States Renal Data System 2011 Annual Data
Report: atlas of chronic kidney disease and endstage renal disease in the United States. Am J Kidney D 2012;59:A7, e1-e420.

6 Li L, Terry CM, Blumenthal DK, Kuji T, Masaki T, Kwan BC, Zhuplatov I, Leypoldt JK, Cheung AK: Cellular and morphological changes during neointimal hyperplasia development in a porcine arteriovenous graft model. Nephrol Dial Transplant 2007;22:31393146.

7 Kelly BS, Heffelfinger SC, Whiting JF, Miller MA, Reaves A, Armstrong J, Narayana A, Roy-Chaudhury P: Aggressive venous neointimal hyperplasia in a pig model of arteriovenous graft stenosis. Kidney Int 2002;62: 2272-2280. 
8 Li G, Chen SJ, Oparil S, Chen YF, Thompson JA: Direct in vivo evidence demonstrating neointimal migration of adventitial fibroblasts after balloon injury of rat carotid arteries. Circulation 2000;101:1362-1365.

9 Newby AC, Zaltsman AB: Molecular mechanisms in intimal hyperplasia. J Pathol 2000;190: 300-309.

10 Rekhter M, Nicholls S, Ferguson M, Gordon D: Cell proliferation in human arteriovenous fistulas used for hemodialysis. Arterioscler Thromb 1993;13:609-617.

11 Roy-Chaudhury P, Kelly BS, Miller MA, Reaves A, Armstrong J, Nanayakkara N, Heffelfinger SC: Venous neointimal hyperplasia in polytetrafluoroethylene dialysis grafts. Kidney Int 2001;59:2325-2334.

12 Tomas JJ, Stark VE, Kim JL, Wolff RA, Hullett DA, Warner TF, Hoch JR: Beta-galactosidasetagged adventitial myofibroblasts tracked to the neointima in healing rat vein grafts. J Vasc Res 2003;40:266-275.

13 Asif A, Gadalean FN, Merrill D, Cherla G, Cipleu CD, Epstein DL, Roth D: Inflow stenosis in arteriovenous fistulas and grafts: a multicenter, prospective study. Kidney Int 2005;67: 1986-1992.

14 Bhardwaj S, Roy H, Heikura T, Yla-Herttuala S: VEGF-A, VEGF-D and VEGF$\mathrm{D}$ (DeltaNDeltaC) induced intimal hyperplasia in carotid arteries. Eur J Clin Invest 2005;35: 669-676.

15 Hart CE, Kraiss LW, Vergel S, Gilbertson D, Kenagy R, Kirkman T, Crandall DL, Tickle S, Finney H, Yarranton G, Clowes AW: PDGFbeta receptor blockade inhibits intimal hyperplasia in the baboon. Circulation 1999;99:564569.

16 Khurana R, Zhuang Z, Bhardwaj S, Murakami M, De Muinck E, Yla-Herttuala S, Ferrara N, Martin JF, Zachary I, Simons M: Angiogenesisdependent and independent phases of intimal hyperplasia. Circulation 2004;110:2436-2443.

17 Sirois MG, Simons M, Edelman ER: Antisense oligonucleotide inhibition of PDGFR-beta receptor subunit expression directs suppression of intimal thickening. Circulation 1997;95: 669-676.

18 Walpoth BH, Zammaretti P, Cikirikcioglu M, Khabiri E, Djebaili MK, Pache JC, Tille JC, Aggoun Y, Morel D, Kalangos A, Hubbell JA, Zisch AH: Enhanced intimal thickening of expanded polytetrafluoroethylene grafts coated with fibrin or fibrin-releasing vascular endothelial growth factor in the pig carotid artery interposition model. J Thorac Cardiovasc Surg 2007;133:1163-1170.

19 Haga JH, Li YS, Chien S: Molecular basis of the effects of mechanical stretch on vascular smooth muscle cells. J Biomech 2007;40:947960.

20 Li YS, Haga JH, Chien S: Molecular basis of the effects of shear stress on vascular endothelial cells. J Biomech 2005;38:1949-1971.

21 Mendel DB, Laird AD, Xin X, Louie SG, Christensen JG, Li G, Schreck RE, Abrams TJ, Ngai
TJ, Lee LB, Murray LJ, Carver J, Chan E, Moss KG, Haznedar JO, Sukbuntherng J, Blake RA, Sun L, Tang C, Miller T, Shirazian S, McMahon G, Cherrington JM: In vivo antitumor activity of SU11248, a novel tyrosine kinase inhibitor targeting vascular endothelial growth factor and platelet-derived growth factor receptors: determination of a pharmacokinetic/pharmacodynamic relationship. Clin Cancer Res 2003; 9:327-337.

22 Chow LQ, Eckhardt SG: Sunitinib: from rational design to clinical efficacy. J Clin Oncol 2007; 25:884-896.

23 Kuji T, Masaki T, Goteti K, Li L, Zhuplatov S, Terry CM, Zhu W, Leypoldt JK, Rathi R, Blumenthal DK, Kern SE, Cheung AK: Efficacy of local dipyridamole therapy in a porcine model of arteriovenous graft stenosis. Kidney Int 2006;69:2179-2185.

24 Terry CM, Li L, Li H, Zhuplatov I, Blumenthal DK, Kim SE, Owen SC, Kholmovski EG, Fowers KD, Rathi R, Cheung AK: In vivo evaluation of the delivery and efficacy of a sirolimus-laden polymer gel for inhibition of hyperplasia in a porcine model of arteriovenous hemodialysis graft stenosis. J Control Release 2012;160:459467.

25 Terry CM, Blumenthal DK, Sikharam S, Li L, Kuji T, Kern SE, Cheung AK: Evaluation of histological techniques for quantifying haemodialysis arteriovenous (AV) graft hyperplasia. Nephrol Dial Transplant 2006;21:3172-3179.

26 Clerin V, Gusic RJ, O’Brien J, Kirshbom PM, Myung RJ, Gaynor JW, Gooch KJ: Mechanical environment, donor age, and presence of endothelium interact to modulate porcine artery viability ex vivo. Ann Biomed Eng 2002;30:11171127.

27 Gusic RJ, Myung R, Petko M, Gaynor JW, Gooch KJ: Shear stress and pressure modulate saphenous vein remodeling ex vivo. J Biomech 2005;38:1760-1769.

28 Joddar B, Shaffer RJ, Reen RK, Gooch KJ: Arterial $\mathrm{pO}_{2}$ stimulates intimal hyperplasia and serum stimulates inward eutrophic remodeling in porcine saphenous veins cultured ex vivo. Biomech Model Mechanobiol 2011;10:161175.

29 Ishida A, Murray J, Saito Y, Kanthou C, Benzakour O, Shibuya M, Wijelath ES: Expression of vascular endothelial growth factor receptors in smooth muscle cells. J Cell Physiol 2001;188: 359-368.

30 Chanakira A, Dutta R, Charboneau R, Barke R, Santilli SM, Roy S: Hypoxia differentially regulates arterial and venous smooth muscle cell proliferation via PDGFR- $\beta$ and VEGFR-2 expression. Am J Physiol Heart Circ Physiol 2012; 302:H1173-H1184.

31 Cheng C, Haasdijk RA, Tempel D, den Dekker WK, Chrifi I, Blonden LA, van de Camp EH, de Boer M, Bürgisser PE, Noorderloos A, Rens JA, ten Hagen TL, Duckers HJ: PDGF-induced migration of vascular smooth muscle cells is inhibited by heme oxygenase-1 via VEGFR-2 upregulation and subsequent assembly of inactive
VEGFR2/PDGFR $\beta$ heterodimers. Arterioscler Thromb Vasc Biol 2012;32:1289-1298.

32 Franke TF, Yang SI, Chan TO, Datta K, Kazlauskas A, Morrison DK, Kaplan DR, Tsichlis PN: The protein kinase encoded by the Akt proto-oncogene is a target of the PDGF-activated phosphatidylinositol 3-kinase. Cell 1995;81: 727-736.

33 van Dijk MC, Hilkmann H, van Blitterswijk WJ: Platelet-derived growth factor activation of mitogen-activated protein kinase depends on the sequential activation of phosphatidylcholine-specific phospholipase $\mathrm{C}$, protein kinase C-zeta and Raf-1. Biochem J 1997;325:303-307.

34 Ruvinsky I, Mayuhas O: Ribosomal protein S6 phosphorylation: from protein synthesis to cell size. Trends Biochem Sci 2006;31:342-348.

35 Ishii S, Okamoto Y, Katsumata H, Egawa S, Yamanaka D, Fukushima M, Minami S: Sunitinib, a small-molecule receptor tyrosine kinase inhibitor, suppresses neointimal hyperplasia in balloon-injured rat carotid artery. J Cardiovasc Pharmacol Ther 2013;18:359-366.

36 Li L, Blumenthal DK, Masaki T, Terry CM, Cheung AK: Differential effects of imatinib on PDGF-induced proliferation and PDGF receptor signaling in human arterial and venous smooth muscle cells. J Cell Biochem 2006;99: 1553-1563.

37 Porter KE, Varty K, Jones L, Bell PR, London NJ: Human saphenous vein organ culture: a useful model of intimal hyperplasia? Eur J Vasc Endovasc Surg 1996;11:48-58.

38 Soyombo AA, Angelini GD, Bryan AJ, Jasani B, Newby AC: Intimal proliferation in an organ culture of human saphenous vein. Am J Pathol 1990;137:1401-1410.

39 Rotmans JI, Heyligers JM, Verhagen HJ, Velema E, Nagtegaal MM, de Kleijn DP, de Groot FG, Stroes ES, Pasterkamp G: In vivo cell seeding with anti-CD34 antibodies successfully accelerates endothelialization but stimulates intimal hyperplasia in porcine arteriovenous expanded polytetrafluoroethylene grafts. Circulation 2005;112:12-18.

40 Lee T, Chauhan V, Krishnamoorthy M, Wang Y, Arend L, Mistry MJ, El-Khatib M, Banerjee R, Munda R, Roy-Chaudhury P: Severe venous neointimal hyperplasia prior to dialysis access surgery. Nephrol Dial Transplant 2011;26: 2264-2270

41 Kokubo T, Ishikawa N, Uchida H, Chasnoff SE, Xie X, Mathew S, Hruska KA, Choi ET: CKD accelerates development of neointimal hyperplasia in arteriovenous fistulas. J Am Soc Nephrol 2009;20:1236-1245.

42 Langer S, Kokozidou M, Heiss C, Kranz J, Kessler T, Paulus N, Krüger T, Jacobs MJ, Lente C, Koeppel TA: Chronic kidney disease aggravates arteriovenous fistula damage in rats. Kidney Int 2010;78:1312-1321.

43 Wang Y, Liang A, Luo J, Liang M, Han G, Mitch WE, Cheng J: Blocking Notch in endothelial cells prevents arteriovenous fistula failure despite CKD. J Am Soc Nephrol 2014;25:773783. 